\title{
Analysis of Domestic Bitcoin Market Based on Granger Causality Test and Regression Analysis
}

\author{
Si Chen ${ }^{1+}$, Lingli Duan ${ }^{1}$, Wenyi Zhang ${ }^{1}$, Jiayuan Zhang $^{1}$, and Chanjuan Xiao ${ }^{1}$ \\ ${ }^{1}$ Beijing University of Posts and Telecommunications No.10 Xi Tu Cheng Road, Haidian District, Beijing, \\ China
}

\begin{abstract}
Domestic bitcoin trading volume, which represents the current situation of domestic bitcoin market, is used to analyze it together with a variety of variables. After all the variables pass the stationarity test and co-integration test, the Granger causality test and the regression analysis are used to analyze the status of the domestic bitcoin market. According to Granger causality test, there is no evidence that bitcoin prices can affect the development of domestic bitcoin market. According to the regression analysis, it can be seen that the bitcoin stock, the circulation of RMB and the exchange rate of USD to RMB are positively related to the bitcoin transaction volume, and the improvement of the bitcoin market environment will suppress the bitcoin transaction.
\end{abstract}

Keywords: bitcoin, granger causality test, regression analysis, market environment

\section{Literature Review}

Brito, Shadab, and Castillo (2013) [1] defined bitcoin as an Internet protocol, a peer-to-peer network. At present, domestic bitcoin market accounts for about $80 \%$ of that of the world [2]. Studies based on bitcoin have focused on the following aspects.

The first aspect is the study of the transaction of bitcoin. Wang (2014) [3] said that whether in the long term or short term, the trading volume of bitcoin would not affect its price. Chen Hao (2015) [4] pointed out that the transaction volume of bitcoin reflected its market trade. We will use the bitcoin trading volume to quantify the current status of domestic bitcoin market.images in Word, position the cursor at the insertion point and either use Insert | Picture | From File or copy the image to the Windows clipboard and then Edit | Paste Special | Picture (with "Float over text" unchecked).

The second aspect is the legal research of bitcoin. Hendrickson, Hogan, Luthe (2015) [5] studied the political economy of bitcoin, and the result showed that the prohibition of government on bitcoin must be in a certain scale to ensure its validation, and the threshold depended on the number of people willing to accept bitcoin. Marian (2014) [6] said that the government's increased investment in the security of bitcoin would help reduce the illegal use of bitcoin. We will consider the impact of the bitcoin market environment on the development of bitcoin market in China.

The third aspect is the study of the price of bitcoin. Smith (2015) [7] confirmed that there was no direct law between the price of bitcoin and exchange rates between different currencies. We will analyze whether the CNY price of bitcoin influences domestic bitcoin market.

The fourth aspect is to discuss whether the bitcoin is a real currency. Yermack (2014) [8] concluded that bitcoin was not a currency at the present stage from three monetary functions of a currency. Desan (2014) [9] proposed that according to the trend of bitcoin price, bitcoin was more likely a speculative commodity. Trades in domestic bitcoin market that we focus are mainly from the purpose of speculation.

\footnotetext{
+ Corresponding author. Tel.: +86-13021121277

E-mail address: angela_mis@163.com
} 
In this paper, we will focus on domestic bitcoin market, analyzing its current situation.

\section{Data}

Following variables are analyzed as dependent variable and independent variables. The sample data interval is selected from November 2011 to June 2016. The data sources and processings are as follows.

DBT (Domestic Bitcoin Transaction). The monthly data comes from bitcoinity.com.

BPC (Bitcoin Price in CNY). The data is from the country's largest bitcoin trading site cn.investing.com.

M1 (Domestic RMB Circulation). The monthly data comes from the financial sector of the official website of National Bureau of Statistics, with billion as the unit.

ER (Exchange Rate of USD to RMB). The monthly data is from the official website of central bank, which is the amount of one dollar equivalent to RMB.

En (Market Environment). News of bitcoin comes from the Internet. This is quantified as $0, \pm 10, \pm 20$, $\pm 30, \pm 40, \pm 50$, according to the degree of promotion or inhibition of the news to the domestic bitcoin market.

BS (Bitcoin Stock). It represents the total amount of bitcoin that has been mined. In this paper we use the bitcoin stock at the end of the month. The data comes from block.okcoin.cn.

\section{Empirical Analysis}

\subsection{Stationarity Test}

The ADF [10] unit root test method is used to test the variables respectively.

Table I: Stationarity Test

\begin{tabular}{l|cccc}
\hline & D.Order & ADF & Prob. & Result \\
\hline DBT & & -7.264624 & 0.0000 & \\
BPC & & -4.05498 & 0.0025 & \\
ER & & -4.949975 & 0.0001 & Integrated \\
M & One & -8.940596 & 0.0000 & of Order \\
En & & -8.373046 & 0.0000 & One \\
BS & & -3.516091 & 0.0117 &
\end{tabular}

It can be seen from Table I that after first-order difference, $p$ values of six variables are minute enough to indicate that the group of variables is a first-order time series, which can be processed by co-integration test.

\subsection{Co-integration Test}

In this paper, Johansen (1991) [11] [12] [13] co-integration test method is used to to determine whether there is a stable equilibrium relationship between all variables.

\begin{tabular}{ccccc}
\multicolumn{5}{c}{ Table II: Co-integration Test } \\
\hline \hline $\begin{array}{c}\text { Hypothesized } \\
\text { No. of CE(s) }\end{array}$ & Eigenvalue & $\begin{array}{c}\text { Trace } \\
\text { Statistic }\end{array}$ & $\begin{array}{c}0.05 \\
\text { Critical Value }\end{array}$ & Prob. $^{* *}$ \\
\hline \hline None * & 0.949766 & 234.8822 & 95.75366 & 0.0000 \\
At most 1 * & 0.656414 & 112.2483 & 69.81889 & 0.0000 \\
At most 2 * & 0.563244 & 68.44727 & 47.85613 & 0.0002 \\
At most 3 * & 0.346220 & 34.48366 & 29.79707 & 0.0134 \\
At most 4 * & 0.246985 & 17.05929 & 15.49471 & 0.0288 \\
At most 5 * & 0.124019 & 5.428838 & 3.841466 & 0.0198 \\
\hline \hline
\end{tabular}

It can be seen from Table II that assumptions of up to zero, one, two, three, four, five pairs of co-integration relationships are all rejected, indicating that there is at least six pairs of co-integration relationships between variables. The Granger causality test can be then used to determine whether there is a causal relationship between the independent variables and the dependent variable.

\subsection{Granger Causality Test}

In this paper, $\mathrm{SC}$ information criterion is used as the criterion of selection lag. The Granger causality relationship between DBT and BPC, ER, M1 and En from 2011-2016 is tested.

From results of Granger causality test, M1, ER, En, BS are Granger reasons for DBT, and there is a two-way Granger causality relationship between En and DBT. In addition, there is no obvious Granger causality relationship between BPC and DBT. 
Table III: Granger Causality Test

\begin{tabular}{c|ccccc}
\hline $\mathrm{H}_{0}$ & ER $\neq>\mathrm{DBT}$ & $\mathrm{DBT} \neq>\mathrm{ER}$ & $\mathrm{M}_{1} \neq>\mathrm{DBT}$ & $\mathrm{DBT} \neq>\mathrm{M}_{1}$ & En $\neq>\mathrm{DBT}$ \\
$\begin{array}{c}\text { F-statistic } \\
\text { P-value }\end{array}$ & 5.50201 & 1.48179 & 4.65569 & 1.41052 & 3.67427 \\
outcome & 0.0070 & 0.2372 & 0.0141 & 0.2537 & 0.0326 \\
\multicolumn{1}{|c|}{ Reject } & Accept & Reject & Accept & Reject \\
\hline $\mathrm{H}_{0}$ & $\mathrm{DBT} \neq>\mathrm{En}$ & $\mathrm{BS} \neq>\mathrm{DB} 1$ & $\mathrm{DBT} \neq>\mathrm{BS}$ & $\mathrm{BPC} \neq>\mathrm{DBT}$ & $\mathrm{DBT} \neq>\mathrm{BPC}$ \\
$\mathrm{F}$-statistic & 3.25330 & 3.53943 & 0.79412 & 0.38048 & 0.83725 \\
P-value & 0.0471 & 0.0378 & 0.4585 & 0.6857 & 0.4395 \\
outcome & Reject & Reject & Accept & Accept & Accept
\end{tabular}

We hypothesized that the CNY price of bitcoin was one of the factors affecting the domestic bitcoin market, and thus launched multiple Granger causality tests based on different processings of BPC. In Fig. 3, we used the monthly average of the CNY price of bitcoin for the test. It can be seen that there is no sufficient evidence that the CNY price of bitcoin can influence the domestic bitcoin market. This overturns our initial speculation that the CNY price of the bitcoin can affect the domestic bitcoin market.

Wang (2014) [3] also gave similar conclusions. He pointed out that when bitcoin was used for trading purposes, its prices would not fluctuate drastically. But when bitcoin was used for storage purposes, its price would change.

\subsection{Regression Analysis}

Table IV: Regression Analysis

\begin{tabular}{lrrrr}
\hline \multicolumn{1}{c}{ Variable } & Coefficient & Std. Error & t-Statistic & Prob. \\
\hline \hline BS & 6.853685 & 4.390578 & 1.560999 & 0.1251 \\
M1 & 18.09633 & 252.8007 & 0.071583 & 0.9432 \\
ER & $1.32 \mathrm{E}+08$ & 32285849 & 4.091657 & 0.0002 \\
EN & -94313.85 & 135801.5 & -0.694498 & 0.4907 \\
C & $-9.03 \mathrm{E}+08$ & $1.78 \mathrm{E}+08$ & -5.073352 & 0.0000 \\
\hline \hline R-squared & 0.719605 & Mean dependent var & 13216846 \\
Adjusted R-squared & 0.696238 & S.D. dependent var & 27137002 \\
S.E. of regression & 14956443 & Akaike info criterion & 35.96877 \\
Sum squared resid & $1.07 \mathrm{E}+16$ & Schwarz criterion & 36.15465 \\
Log likelihood & -948.1724 & Hannan-Quinn criter. & 36.04025 \\
F-statistic & 30.79672 & Durbin-Watson stat & 1.966124 \\
Prob(F-statistic) & 0.000000 & & & \\
\hline \hline
\end{tabular}

From the results of the multiple regression analysis in Table IV, it can be seen that the increase of 1 BTC in BS will cause DBT to increase by about 6 BTC, and the increase of M1 of 1 RMB will cause DBT to increase by about $18 \mathrm{BTC}$, and the increase of USD in $100000 \mathrm{RMB}$ will cause DBT to increase by about 1320BTC, whreas En and DBT are negatively correlated.

\section{Result Analysis}

First of all, the exchange rate of USD to RMB, bitcoin stock, the RMB circulation are all Granger reasons of the development of domestic bitcoin market.

Till 2015, the exchange rate of USD to RMB continued to decline, which promoted people's investment in hedge. At this time, the bitcoin market was hot, so a large number of investors joined the transaction of this limited resource. In addition, the investment demand increased due to the increase in disposable income. Consequently, it is not difficult to understand the increase in the circulation of RMB indirectly contributed to the investment demand. Trading bitcoin, as one of the high-yield investment approaches, nourished naturally. The increase in circulation of RMB, the depreciation of the dollar, bitcoin becoming more scarce stimulated the growth of bitcoin transaction altogether.

Secondly, there is a two-way Granger causality relationship between the bitcoin market environment and the domestic bitcoin trading volume.

- The bitcoin market environment is the Granger reason for the domestic bitcoin trading volume

Bitcoin market environment involves both policies of government and social developments.

The trustworthiness index [14] of China ranks first in 28 major economies and regions. The high confidence of the Chinese people in the government to a certain extent explains that environmental change is an important influencing factor on the public when making investment decisions. The regression analysis 
shows that the bitcoin market environment are negatively correlated with the volume of domestic bitcoin transactions.

When the environment is benign, from the perspective of investors, the risk of holding bitcoin will be reduced by events such as the introduction of friendly policies or the release of good news from social institutions, which will have two effects on investors. One is to hold an optimistic attitude to the market and transact positively, the other is to become more confident about the future of bitcoin and hold it. Plus, since the unexploited bitcoin are less and less, current bitcoin owners may choose to wait for a better opportunity for transaction, so the trading volume of bitcoin will decline. Currently, the attitude to hold bitcoin is outweighs the willing to sell it, so the domestic bitcoin trading volume will decline.

On the contrary, when the bitcoin environment deteriorates, the public's risks of holding bitcoin will increase as a result of the government's tight policy. On one hand, the increase in risk will stop the potential buyers from trading, which causes the market trading volume to decline. On the other hand, holders will be more skeptical of the hedge ability of bitcoin, thus choose to sell them as soon as possible. In China, choices of selling bitcoin are more prevail than those of trading conservatively, so domestic bitcoin trading volume will rise sharply.

- The domestic bitcoin trading volume is the Granger reason for the bitcoin market environment

Changes in the bitcoin market also affect environmental changes. When the bitcoin market develops well, a number of bitcoin trading platforms will emerge, and more and more mainstream institutions will also accept bitcoin as payment. From the point of view of the government, it has to take direct or indirect considerations of the changes in domestic bitcoin trading volume into account for its attribute of decentralization. Therefore, both the government and enterprises, when forming policies and implementing strategies, will be to some extent influenced by the domestic bitcoin trading volume.

As a consequence, when there exists a certain subjective degree when quantifying the environmental variable, we draw a two-way negative correlation between the bitcoin market environment and the domestic bitcoin trading volume. Undoubtedly, the environmental variable stand out among other factors, and it is worth attention from the policy makers, business decision makers, and investors.

\section{Conclusion}

There are four factors that can be attributed as influencing factors of the domestic bitcoin market: the market environment, the bitcoin stock, the circulation of RMB and the exchange rate of USD to RMB. Initially, we predicted that the CNY price of bitcoin would affect the bitcoin trading volume, however, it was denied by Granger causality test.

The empirical analysis shows that bitcoin market environment in China poses a negative impact on domestic bitcoin market. Overall, Chinese government holds a conservative attitude to bitcoin. On one hand paying close attention to the development of bitcoin, and on the other hand denying the legitimacy of it. Based on this, we believe that future policies of Chinese government on bitcoin will be highly linked with the market to ensure a safe and stable development of cryptocurrency with bitcoin as its representative.

\section{Acknowledgement}

This work is funded by Research Innovation Fund for College Students of Beijing University of Posts and Telecommunications; Special Project of Beijing Co-Construction Project.

\section{References}

[1] S. Chen, B. Mulgrew, and P. M. Grant, "A clustering technique for digital communications channel equalization using radial basis function networks," IEEE Trans. on Neural Networks, vol. 4, pp. 570-578, July 1993.

[2] J. U. Duncombe, "Infrared navigation-Part I: An assessment of feasibility," IEEE Trans. Electron Devices, vol. ED-11, pp. 34-39, Jan. 1959.

[3] C. Y. Lin, M. Wu, J. A. Bloom, I. J. Cox, and M. Miller, "Rotation, scale, and translation resilient public watermarking for images," IEEE Trans. Image Process., vol. 10, no. 5, pp. 767-782, May 2001. 
[4] A. Cichocki and R. Unbehaven, Neural Networks for Optimization and Signal Processing, 1st ed. Chichester, U.K.: Wiley, 1993, ch. 2, pp. 45-47.

[5] W.-K. Chen, Linear Networks and Systems, Belmont, CA: Wadsworth, 1993, pp. 123-135.

[6] H. Poor, An Introduction to Signal Detection and Estimation; New York: Springer-Verlag, 1985, ch. 4.

[7] R. A. Scholtz, "The Spread Spectrum Concept," in Multiple Access, N. Abramson, Ed. Piscataway, NJ: IEEE Press, 1993, ch. 3, pp. 121-123.

[8] G. O. Young, "Synthetic structure of industrial plastics," in Plastics, 2nd ed. vol. 3, J. Peters, Ed. New York: McGraw-Hill, 1964, pp. 15-64.

[9] M. B. Kasmani, "A Socio-linguistic Study of Vowel Harmony in Persian (Different Age Groups Use of Vowel Harmony Perspective," International Proceedings of Economics Development and Research, ed. Chen Dan, pp. 359-366, vol. 26, 2011.

[10] W. D. Doyle, "Magnetization reversal in films with biaxial anisotropy," in Proc. 1987 INTERMAG Conf., 1987, pp. 2.2-1-2.2-6.

[11] G. W. Juette and L. E. Zeffanella, "Radio noise currents n short sections on bundle conductors," presented at the IEEE Summer Power Meeting, Dallas, TX, June 22-27, 1990.

[12] Transmission Systems for Communications, 3rd ed., Western Electric Co., Winston-Salem, NC, 1985, pp. 44-60.

[13] Motorola Semiconductor Data Manual, Motorola Semiconductor Products Inc., Phoenix, AZ, 1989.

[14] J. Brito, H. Shadab, A. Castillo. (April 2015). Bitcoin Financial Regulation: Securities, Derivatives, Prediction Markets, and Gambling. Available: https://ssrn.com/abstract=2423461

[15] Tsinghua PBCSF Fintech Lab, huobi.com, tech.sina.com.cn. (July 2016). A Study Report on the Development of Global Bitcoin in 2014-2016. Available: http:/www.useit.com.cn/thread-12842-1-1.html

[16] J.C. Wang. A simple macroeconomic model of bitcoin. [J]Bitquant Research Laboratories Working Paper. 2014 , pp.1.

[17] H. Chen, “The Econimic Analysis of Bitcoin”. Ph.D. dissertation, Dept. Elect. Chn., MA, Zhejiang Univ., Hangzhou, Zhejiang, 2015.

[18] J. Hendrickson, T. Hogan, W. Luther. (July 2015). The Political Economy of Bitcoin. Available: https://ssrn.com/abstract=2531518

[19] O. Marian. (2015). A Conceptual Framework for the Regulation of Cryptocurrencies. Available: https://ssrn.com/abstract=2509857

[20] J. Smith. (May 2016). An Analysis of Bitcoin Exchange Rates. Available: https://ssrn.com/abstract=2493797

[21] D. Yermack. (April 2014). Is Bitcoin a Real Currency? An Economic Appraisal. Available: https://ssrn.com/abstract=2361599

[22] C. Desan. (April 2012). Is Bitcoin Money? Bitcoin and Alternative Theories of Money. Available: https://ssrn.com/abstract=2434194

[23] D. Dickey, W. A Fuller. Distribution of the Estima-tors for Autoregressive Time Series with a Unit Root [J]. Journal of American Statistical Association, 745: 427- 431, 1979

[24] S. Johansen. Statistical Analysis of Cointegration Vectors. Journal of Economic Dynamics and Control. vol. 12.2-3, pp: 231-254, 1988

[25] S. Johansen. Estimation and Hypothesis Testing of Cointegration Vectors in Gaussian Vector Autoregressive Models. Econometrica. vol 59.6, pp: 80, 1991

[26] S. Johansen. A Statistical Analysis for Cointegration for I(2) Variables. Econometric Theory. vol. 11.1, pp: 25-59,1995

[27]Edelman. (2016). 2016 Edelman mjTrust Barometer. Available: http://www.edelman.com/insights/intellectual-property/2016-edelman-trust-barometer 